\title{
Supporting Young Researcher Families in Switzerland
}

\author{
Maria Podkopaeva and Olga Chekeres (both University of Geneva, Switzerland)
}

The life of a PhD student or postdoc in mathematics (or any other subject) can be challenging in many ways, and more so if you have a family, especially if you have young children. In Switzerland, there exist several institutions that offer help in such situations. Some measures, specifically tuned to young researchers in mathematics and theoretical physics, are proposed by NCCR SwissMAP.

The Swiss National Centre of Competence in Research (NCCR) SwissMAP ${ }^{1}$ is a programme supporting mathematics and theoretical physics in Switzerland, created in the context of the NCCR projects of the Swiss National Science Foundation. It brings together around 40 professors from Swiss universities and CERN and their groups (altogether around 200 people). In addition to its research curriculum, the goal is to attract more talented young people to mathematics and theoretical physics in Switzerland. This is done via a full cycle of educational activities: from a wide variety of outreach projects for schools, some of which have been described in a previous issue of the EMS Newsletter, ${ }^{2}$ through master classes (year-long in-depth Master's level programmes for internationally selected students), to opportunities and training for PhD students and postdocs. NCCR SwissMAP also has several programmes for supporting young researchers with families.

\section{Dual careers}

Everybody knows that the lifestyle of a postdoc (or a student involved in an exchange programme) is not very well suited for someone with a family. The positions are short-term and spouses have their own careers to follow. Obviously, dual career measures are more effective at a higher level but it is not very often that both partners work within the relatively narrow field on the border of mathematics and theoretical physics. When it does happen (so far, in four years of SwissMAP's existence, we've had one case, with a Master's student in mathematics married to an exchange PhD student in physics, and one more case is being discussed right now), we are happy to help by providing dual career scholarships or supporting other arrangements.

\section{Young children}

Being a PhD student or a postdoc with a baby can be tough. If you plan to pursue a career in maths, you have to work on your $\mathrm{CV}$, publish papers and participate in conferences, schools and workshops, often abroad. You

\footnotetext{
1 http://nccr-swissmap.ch/.

2 EMS Newsletter No. 100, June 2016.
}

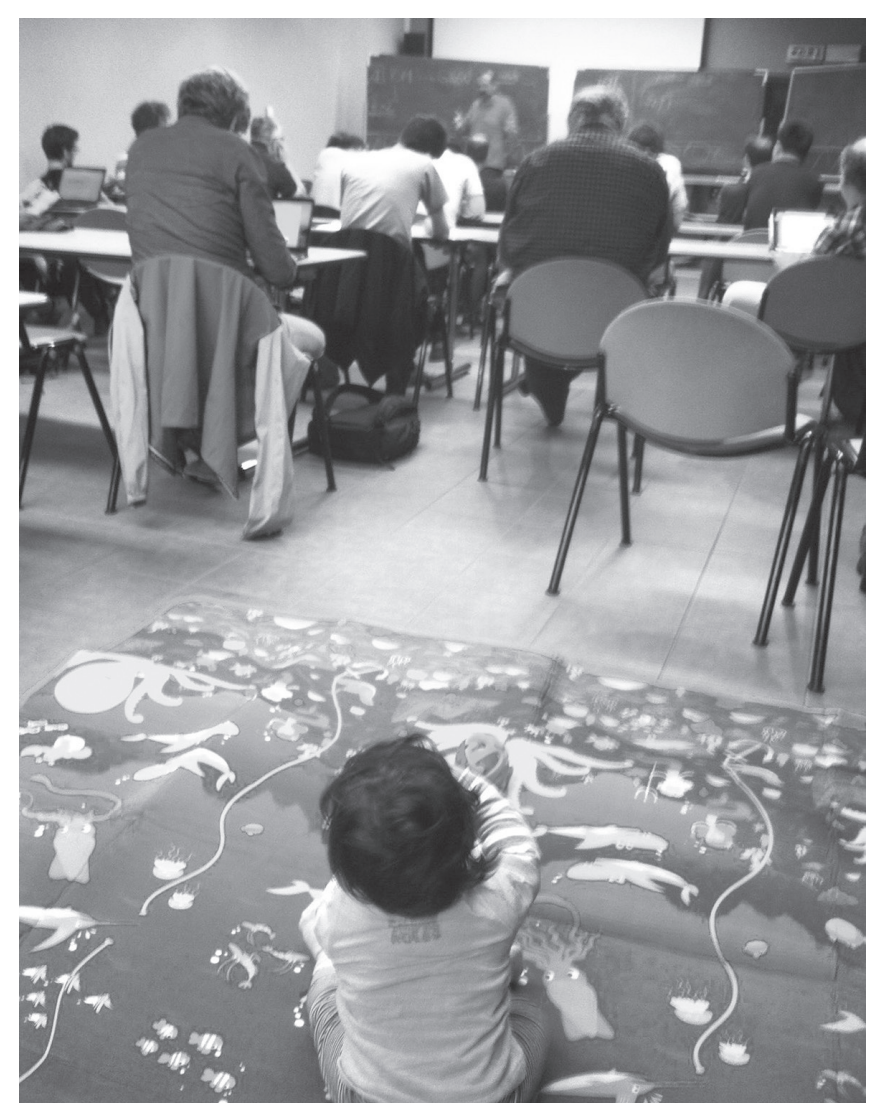

are probably also expected to teach, since part of your salary usually comes from being hired in your department as a teaching assistant. All this can be a major challenge if you are a young mother: first, you are out of the game for the several months of your maternity leave and then, even if you have a place at kindergarten, you still need (and want!) to spend lots of time with your child. During their first year, there are all-night feedings, teething, upset stomachs, etc., and later on, you need to keep up with an energetic toddler. This does not leave much space for research.

To help, we have introduced several schemes of support. In the mobility aspect, if you want to attend a conference or a school, SwissMAP proposes covering the extra costs for travelling with your baby or temporary childcare while you are away. The same is offered to external researchers who visit events organised by SwissMAP.

Last year, we launched the "buy out of teaching" grants. $^{3}$ Once again, when you are an assistant at university, in addition to your research you have teaching

\footnotetext{
3 http://nccr-swissmap.ch/articles/family-support-grants.
} 
duties, which often take a lot of time: the TA sessions themselves, plus the preparation, plus correcting homework... With SwissMAP family support grants, young mothers can be liberated from their teaching (or other non-research) duties so that they do not have to sacrifice their research time, which is already decreased because of their new function as a mother. After all, research is the priority of a scientist and, unlike teaching, it is hard to catch up if you take a long break.

The first person to receive such a grant was Olga Chekeres, a PhD student in Geneva, whose son was born in February 2017. Here is what she thinks about the mother/PhD student duality.

You are a mother of two, one of whom is still a baby. How does this affect your work as a PhD student? What are the main challenges?

As a mother of two children, with one still a baby, I experience great difficulties managing time, like any working mom I guess. Every day, I have to bring the baby to the daycare in the morning and then not to be late to pick him up in the evening; my effective working hours are reduced. Also, when I am at home, normally there is no way I can do anything for my research - do some reading or write down something - and this is a lot of time gone from my PhD.

Another problem is psychological - to manage making plans. It seems simple, but it took me some time to realise that I don't belong to myself. I have to fix it in my mind that when I leave the office I allow myself not to work, because this time belongs to my kids. And if it happens that the baby goes to bed early and easily and gives me time to enjoy doing something for my project, I would rather take this as a happy bonus, instead of making plans to get him to sleep at 21:00 and then being upset if this doesn't work.

And, of course, finances. The nursery consumes a significant part of the income.

Were Swiss MAP programmes for supporting families useful for you? In what way?

SwissMAP programmes were really useful. One of them liberated me from giving classes, compensating the teaching part of my salary. It really helps to focus more on my research, since my working time is reduced.

Another programme reimburses the expenses for a daycare centre or a baby-sitter if I attend a conference, which is really a great thing, allowing me to stay updated and to participate in academic life.

Do you see other aspects of reconciling family life and your career, where SwissMAP or your university could help?

Actually, any financial support is always useful.

Organising a parking space for working moms might be helpful. For me, this problem was solved with the help of a friend, otherwise renting a place or paying per hour is extremely expensive. Without a car, there is no mobility to come quickly to the nursery if anything happens,

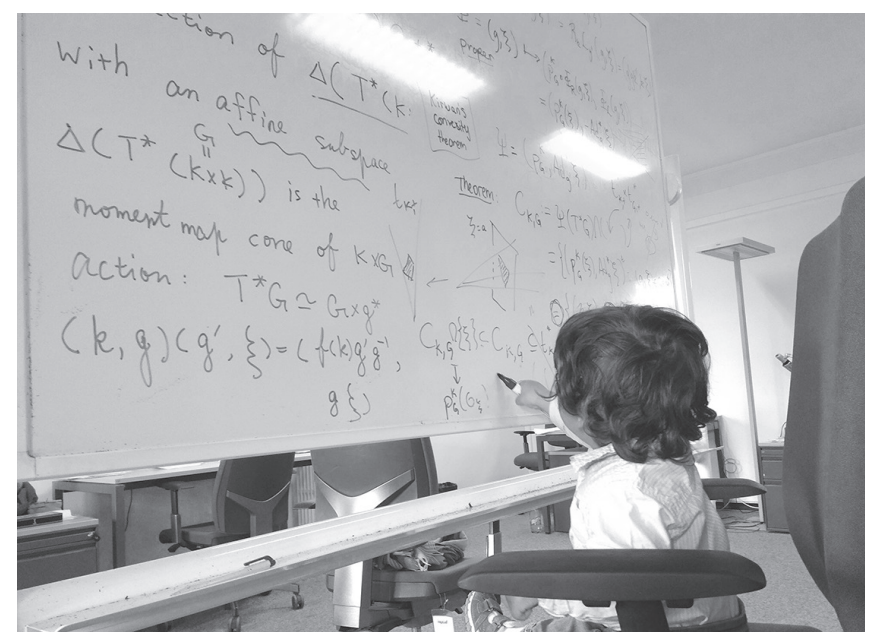

to bring the baby to a doctor and then return back to work, etc., etc. And even on a daily basis, just the trajectory home - nursery - office would consume much more working time, which is already reduced.

Our aim is to be as flexible as possible when it comes to supporting young researchers. The schemes described above are already formalised and functioning but we always keep our eyes open for new ideas and try to find a way to help in any special situations (thankfully, the Swiss Science Foundation is usually quite forthcoming with respect to such a personalised approach).

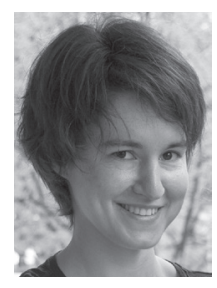

Maria Podkopaeva is a research associate at the University of Geneva working as a science officer for NCCR SwissMAP. She obtained her PhD at the University of Geneva in 2012.

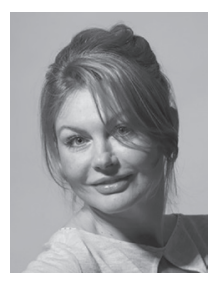

Olga Chekeres is a PhD student at the University of Geneva under the supervision of Anton Alekseev. Her research field is mathematical physics. 